CARDIOVASCULAR MEDICINE

\title{
Can we define patients with no chance of survival after out- of-hospital cardiac arrest?
}

\author{
J Herlitz, J Engdahl, L Svensson, M Young, K-A Ängquist, S Holmberg
}

Heart 2004;90:1114-1118. doi: 10.1136/hrt.2003.029348

See end of article for authors' affiliations

....................

Correspondence to: Dr Johan Herlitz, Division of Cardiology, Sahlgrenska Úniversity Hospital, S-413 45 Göteborg Sweden; johan.herlitz@hil.gu.se

Accepted

14 February 2004

\begin{abstract}
Objective: To evaluate whether subgroups of patients with no chance of survival can be defined among patients with out-of-hospital cardiac arrest.

Patients: Patients in the Swedish cardiac arrest registry who fulfilled the following criteria were surveyed: cardiopulmonary resuscitation (CPR) was attempted; the arrest was not crew witnessed; and patients were found in a non-shockable rhythm.

Setting: Various ambulance organisations in Sweden.

Design: Prospective observational study.

Results: Among the 16712 patients who fulfilled the inclusion criteria, the following factors were independently associated with a lower chance of survival one month after cardiac arrest: no bystander CPR; non-witnessed cardiac arrest; cardiac arrest occurring at home; increasing interval between call for and arrival of the ambulance; and increasing age. When these factors were considered simultaneously two groups with no survivors were defined. In both groups patients were found in a non-shockable rhythm, no bystander CPR was attempted, the arrest was non-witnessed, the arrest took place at home. In one group the interval between call for and arrival of ambulance exceeded 12 minutes. In the other group patients were older than 80 years and the interval between call for and arrival of the ambulance exceeded eight minutes.

Conclusion: Among patients who had an out-of-hospital cardiac arrest and were found in a nonshockable rhythm the following factors were associated with a low chance of survival: no bystander CPR, non-witnessed cardiac arrest, the arrest took place at home, increasing interval between call for and arrival of ambulance, and increasing age. When these factors were considered simultaneously, groups with no survivors could be defined. In such groups the ambulance crew may refrain from starting CPR.
\end{abstract}

A mong patients who have an out-of-hospital cardiac arrest the overall chance of survival is low. ${ }^{1-4}$ Various factors associated with survival have been defined. ${ }^{25}$ The most important factor for survival is the initial rhythm observed on admission by the ambulance crew. ${ }^{67}$ Thus, patients found in ventricular fibrillation have a much higher survival rate than patients found in a non-shockable rhythm. ${ }^{6-8}$ Patients found in a non-shockable rhythm have a very low chance of survival, reported to be about $2 \%{ }^{9-13}$ It is also important to stress that the vast majority of patients who have an out-of-hospital cardiac arrest are found in a nonshockable rhythm by most emergency medical services around the world. ${ }^{2}{ }^{13-16}$ This knowledge raises the question whether in this population of patients subgroups can be defined that have no chance of survival and therefore whether cardiopulmonary resuscitation (CPR) efforts may be withdrawn soon after admission by the ambulance crew or not even started by the ambulance crew. In this survey we evaluated factors associated with survival among patients who have had an out-of-hospital cardiac arrest that was not crew witnessed, in whom CPR was attempted, and who were found in a non-shockable rhythm by the arriving ambulance crew. Our hypothesis was that such factors can be defined and that on the basis of such knowledge subsets of patients who have an out-of-hospital cardiac arrest can be defined in whom CPR efforts can be withheld soon after arrival of the ambulance crew.

\section{PATIENTS AND METHODS Patients}

Patients with cardiac arrest for whom the ambulance was called were registered, with the exception of patients who had obviously been dead for a long time and whose bodies were not brought to hospital by the ambulance crew. For the others, the standardised form was completed by the ambulance crew. In this survey, crew witnessed cases and patients in whom CPR was not started were excluded. Furthermore, patients were to be found in a non-shockable rhythm. Patients who had a cardiac arrest within hospitals in the community were not included. However, sometimes the ambulance was called upon to service houses and other institutions and these patients were included.

\section{Registry}

This study is based on a material collected by the Swedish cardiac arrest registry, which is a collaboration between The Federation of Leaders in Swedish Ambulance and emergency services and the working group on CPR within the Swedish Society of Cardiology. Since 1993 the registry has been funded by the National Board of Health and Welfare. The registry, which is voluntary, started in 1990 with a few ambulance services. More services have successively joined and in 1995 the registry was based on reports from 57 ambulance services. These services cover $85 \%$ of the 8.7 million inhabitants of Sweden. This survey covered the time between 1990 and 2001.

\section{Study design}

For each case of out-of-hospital cardiac arrest, the ambulance crew (mostly two people, usually one of whom is a nurse) filled in a form with information such as age, place of arrest, probable background to the arrest, bystander occupation (for example lay person, policeman, or a nurse), and a standardised description of the resuscitation procedure, including 
intervention times and interventions such as bystander CPR (a bystander was defined as someone starting CPR before the arrival of the first ambulance, regardless of profession), defibrillation, intubation, drug treatment, and status at the first contact. In ambulances with manual defibrillators, the rhythm was defined as ventricular fibrillation, pulseless electrical activity, or asystole. For automated external defibrillators, the rhythm was defined as shockable rhythm (ventricular fibrillation) or non-shockable rhythm. In this study, ventricular fibrillation includes pulseless ventricular tachycardia. To establish the time of cardiac arrest in witnessed cases, the ambulance crew was instructed to interview the bystanders about the delay from arrest to call. It was stressed in written instructions that a maximum effort had to be made to obtain these times. The ambulance crew recorded the time of arrival at the patient's side, the time of starting CPR, the time of the first defibrillation, the time of a palpable pulse, the time of starting transport to hospital, and the time of arrival at hospital. The number of direct current shocks was recorded. The ambulance crew also classified the cause of the arrest in nine diagnostic categories (heart disease, lung disease, trauma, drug overdose, suicide, drowning, suffocation, sudden infant death syndrome, and other) based on clinical assessment and bystander information. Their diagnosis was accepted for this study and was not verified further among initial survivors during hospitalisation. Immediate outcome was reported by the ambulance crew as dead on arrival, dead in the emergency room, or admitted alive to hospital. The form was filled in during and immediately after the acute event. Each form was sent to the medical director and a copy was sent to the central registry in Göteborg. Another copy was subsequently sent with additional information about whether the patient was dead or alive after one month. Any uncertainty about survival this was controlled according to the National Registry of Deaths. All data were entered on a database in Göteborg. Adherence to the protocol was not absolutely validated, as it would have been extremely complicated and expensive to do this in the various ambulance districts. Instead, a questionnaire was sent to all the medical directors of the ambulance organisations participating in the registry. They were asked to estimate the accuracy of the representation of the study population. They estimated the percentage of the study population that was wrongly omitted from the study in their own district. Percentages from this survey varied from $0 \%$ to $30 \%$ (mean $5 \%$ ).

\section{Statistical methods}

Distributions of variables are given as percentages and median.

For comparison between groups of dichotomous variables Fisher's exact test was used. ${ }^{17}$ A probability value of $\mathrm{p}<0.05$ was regarded as significant. Results were expressed as odds ratio and $95 \%$ confidence intervals.

A stepwise logistic regression was used to select independent predictors to dichotomous dependent variables. In the multivariate analysis the following factors associated with survival in univariate analysis $(p<0.2)$ were entered in the model: age (continuous variable), cause (cardiac versus noncardiac), place (at home versus not at home), bystander CPR (yes versus no), and interval between call for and arrival of the ambulance (continuous variable, natural logarithm). Owing to missing information in most variables the multivariable analysis was for only 11560 patients (69\% of the total series). Results were expressed as odds ratio and 95\% confidence intervals.

\section{RESULTS}

In all, there were 38750 reports of out-of-hospital cardiac arrest during the time of the survey. However, among 8111 patients $(21 \%)$ no CPR was attempted by the arriving ambulance crew. In the remaining 30639 patients CPR was attempted. Among them 3374 (11\%) arrests were witnessed by the ambulance crew and therefore excluded from this study. Among the remaining 27265 patients information on the initial rhythm on admission of the ambulance crew was

Table 2 Mortality one month after cardiac arrest in univariate analysis

\begin{tabular}{|c|c|c|c|c|}
\hline Factor & Survival rate & p Value & OR & $95 \% \mathrm{Cl}$ \\
\hline \multicolumn{5}{|l|}{ Age (years) } \\
\hline$>$ Median & $0.7 \%$ & \multirow[t]{2}{*}{$<0.0001$} & \multirow[t]{2}{*}{2.22} & \multirow[t]{2}{*}{1.61 to 3.11} \\
\hline$\leqslant$ Median & $1.4 \%$ & & & \\
\hline \multicolumn{5}{|l|}{ Sex } \\
\hline Male & $1.0 \%$ & \multirow[t]{2}{*}{$>0.2$} & \multirow[t]{2}{*}{1.09} & \multirow{2}{*}{0.78 to 1.50} \\
\hline Female & $1.1 \%$ & & & \\
\hline \multicolumn{5}{|l|}{ Cause } \\
\hline Cardiac & $0.9 \%$ & \multirow{2}{*}{0.011} & \multirow{2}{*}{1.53} & \multirow{2}{*}{1.11 to 2.10} \\
\hline Non-cardiac & $1.4 \%$ & & & \\
\hline \multicolumn{5}{|c|}{ Place where arrest occurred } \\
\hline At home & $0.6 \%$ & \multirow[t]{2}{*}{$<0.0001$} & \multirow[t]{2}{*}{3.21} & \multirow[t]{2}{*}{2.37 to 4.38} \\
\hline Other & $2.0 \%$ & & & \\
\hline \multicolumn{5}{|c|}{ Bystander witnessed arrest } \\
\hline Yes & $1.3 \%$ & \multirow[t]{2}{*}{$<0.0001$} & \multirow[t]{2}{*}{2.12} & \multirow[t]{2}{*}{1.49 to 3.06} \\
\hline No & $0.6 \%$ & & & \\
\hline \multicolumn{5}{|c|}{ Interval between call for and arrival of ambulance (mins) } \\
\hline$\leqslant$ Median & $1.6 \%$ & \multirow[t]{2}{*}{$<0.0001$} & \multirow[t]{2}{*}{4.4} & \multirow{2}{*}{2.92 to 6.80} \\
\hline$>$ Median & $0.4 \%$ & & & \\
\hline \multicolumn{5}{|c|}{ Interval between collapse and call for ambulance (mins) } \\
\hline$\leqslant$ Median & $1.8 \%$ & \multirow[t]{2}{*}{0.0001} & \multirow[t]{2}{*}{2.48} & \multirow[t]{2}{*}{1.57 to 4.00} \\
\hline$>$ Median & $0.6 \%$ & & & \\
\hline \multicolumn{5}{|l|}{ Bystander CPR } \\
\hline Yes & $1.6 \%$ & \multirow[t]{2}{*}{$<0.0001$} & \multirow[t]{2}{*}{2.14} & \multirow[t]{2}{*}{1.57 to 2.92} \\
\hline No & $0.8 \%$ & & & \\
\hline
\end{tabular}

Table 1 Age, sex, and various factors at resuscitation $(n=16712)$

\begin{tabular}{lll}
\hline Characteristic & $\begin{array}{l}\text { Number with missing } \\
\text { information }\end{array}$ & $\begin{array}{l}\text { Median (25\%, 75\% centiles) } \\
\text { or percentage }\end{array}$ \\
\hline Age (years) & 701 & $72(60,79)$ \\
Female patients & 825 & $31 \%$ \\
Cardiac cause & 1382 & $66 \%$ \\
Arrest occurred at home & 195 & $71 \%$ \\
Bystander CPR & 757 & $32 \%$ \\
Bystander witnessed arrest & 1610 & $56 \%$ \\
Interval between call for and arrival of & 717 & $7(4,11)$ \\
ambulance (min) & & $5(2,10)$ \\
Interval between collapse and call for \\
$\begin{array}{l}\text { ambulance among bystander witnessed } \\
\text { cases only (min) }\end{array}$ & 1675 & \\
\hline CPR, cardiopulmonary resuscitation. & &
\end{tabular}


Table 3 Independent predictors for survival

\begin{tabular}{lll}
\hline & \multicolumn{2}{l}{ All patients } \\
\cline { 2 - 3 } & OR & $95 \% \mathrm{Cl}$ \\
\hline Decreasing age (years) & 1.03 & 1.02 to 1.04 \\
Arrest outside home & 2.94 & 2.05 to 4.26 \\
Witnessed arrest & 2.16 & 1.45 to 3.28 \\
Bystander CPR & 1.75 & 1.20 to 2.55 \\
Decreasing interval from call to & 2.65 & 1.96 to 3.60 \\
arrival (units) & & \\
\hline
\end{tabular}

available for 24398 patients (89\%). Among these patients $7686(32 \%)$ were found in ventricular fibrillation and were excluded from the present analyses. This survey deals with the remaining 16712 patients.

\section{Patient characteristics}

Table 1 shows the median age, proportion of female patients, and various factors at resuscitation in all patients.

\section{Predictors of survival in univariate analysis}

The overall survival to one month of patients found in a nonshockable rhythm was $1 \%$ as compared with $8 \%$ of patients found in a shockable rhythm (crew witnessed cases excluded).

Table 2 shows predictors for survival one month after cardiac arrest among all patients. The following criteria were found to be associated with a particularly low chance of survival: high age, cardiac cause, cardiac arrest at home, nonwitnessed cardiac arrest, no bystander CPR, a long interval between call for and arrival of an ambulance, and a long interval between estimated time of collapse and call for the ambulance.

\section{Predictors for survival in multivariate analysis}

The following appeared as independent predictors for a low chance of survival: cardiac arrest at home, non-witnessed cardiac arrest, no bystander CPR, a long interval between call for and arrival of ambulance, and high age (table 3 ).

\section{Survival to one month in relation to interval between} call for and arrival of the ambulance

Figures 1, 2, and 3 show the proportion of survivors in relation to the interval between call for and arrival of the ambulance when simultaneously considering the various factors shown to be associated with survival: bystander CPR, witnessed status, place of cardiac arrest, and age. Figure 1 shows survival in relation to response time of all patients found in a non-shockable rhythm.

Among patients found in a non-shockable rhythm whose arrest was non-witnessed and where no bystander CPR was attempted, survivors were found in all response times subgroups.

However, among patients found in a non-shockable rhythm who did not receive bystander CPR, had a nonwitnessed cardiac arrest, and experienced the arrest at home, none survived if the interval between call for and arrival of the ambulance exceeded 12 minutes (fig 2). If the patients were older than 80 years but all other factors were the same, none survived if the delay exceeded eight minutes (fig 3 ).

\section{DISCUSSION}

Many descriptions have been published of patients brought to hospital by ambulance after pre-hospital resuscitation attempts in whom further resuscitation efforts within hospital are useless. ${ }^{18-25}$ However, we differ in describing patients in whom resuscitation should not be attempted at all.

In this survey we found that the overall survival rate was very low for patients found in a non-shockable rhythm after an out-of-hospital cardiac arrest in Sweden and in whom CPR was attempted. This is in agreement with previous reports. ${ }^{9-13}$

Among these patients the following predicted a particularly low chance of survival:

- Non-witnessed cardiac arrest. This is in agreement with previous reports showing that witnessed status is important to the outcome of patients who have an out-ofhospital cardiac arrest. ${ }^{26-28}$

- No bystander CPR. The impact of bystander CPR on survival has not been specifically addressed among patients who have an out-of-hospital cardiac arrest and are found in a non-shockable rhythm. It appears that also in this subset bystander CPR improves survival. This information is new.

- Cardiac arrest occurring at home. In non-selected populations of patients who have an out-of-hospital cardiac arrest its occurrence at home appears to be a bad sign. ${ }^{29} 30$ Most probably this is explained by a higher co-morbidity in this cohort (RA Waalewijn, thesis, 2002:77) and that other factors at resuscitation are less favourable including witnessed status and attempted bystander CPR. ${ }^{30}$

- A longer interval between call for and arrival of an ambulance. The delay to start of treatment has been

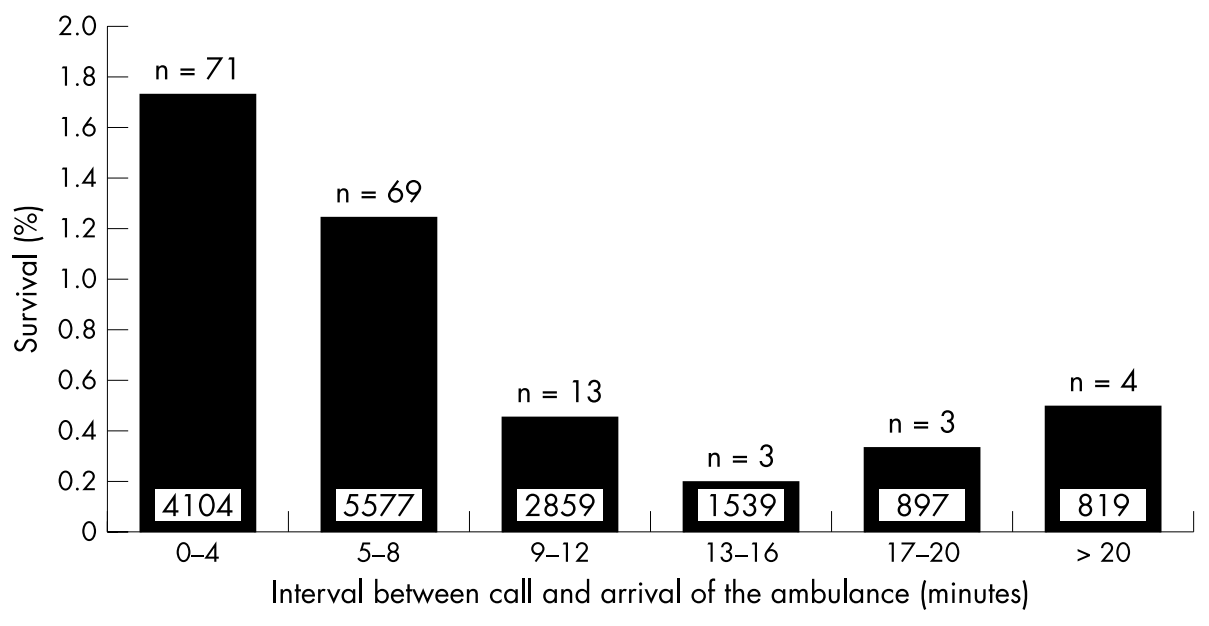

Figure 1 Proportion of patients found in a non-shockable rhythm who survived to one month in relation to the interval between call for and arrival of the ambulance. 


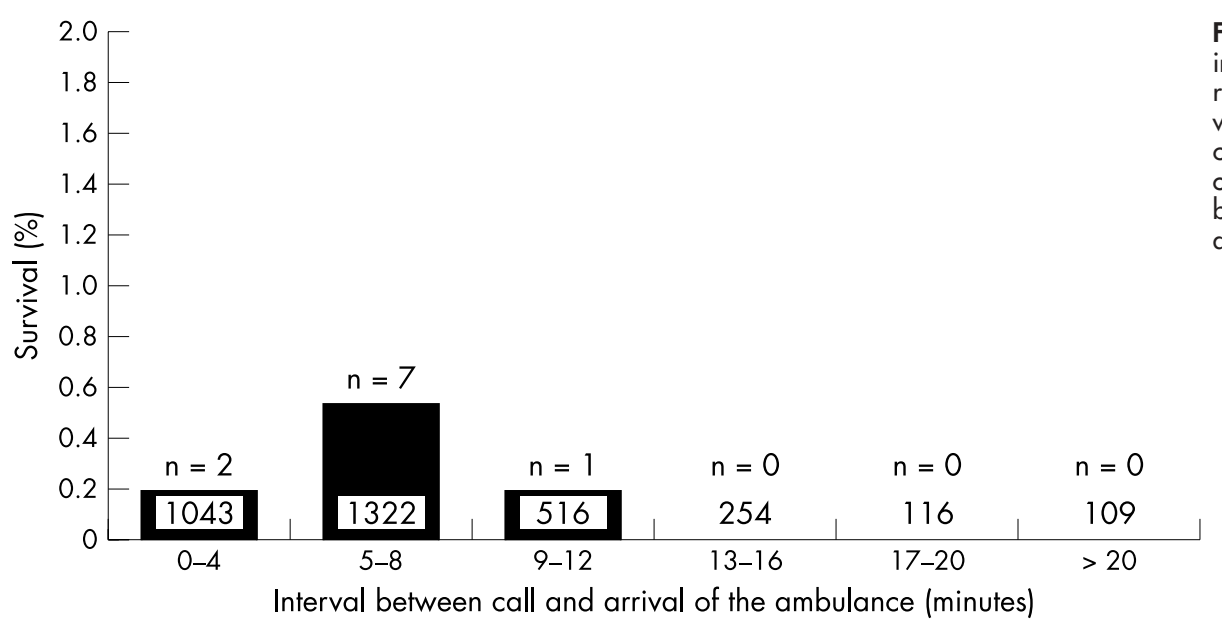

Figure 2 Proportion of patients found in a non-shockable rhythm who did not receive bystander CPR, had a nonwitnessed cardiac arrest, and had a cardiac arrest at home who survived to one month in relation to interval between call for and arrival of the ambulance.

shown to be of ultimate importance among patients found in a either a shockable $e^{31}{ }^{32}$ or a non-shockable rhythm. ${ }^{33}$

- Age. The importance of age for survival after out-ofhospital cardiac arrest has varied in previous surveys. ${ }^{34}{ }^{35}$

No survivor at one month was found among nearly 500 patients fulfilling all of the following criteria: they were found in a non-shockable rhythm; no bystander attempted CPR; the cardiac arrest was not witnessed; the arrest took place at home; the interval between call for and arrival of an ambulance exceeded 12 minutes. However, the chance of survival was also extremely low among patients where these four criteria were fulfilled but the interval between call for and arrival of an ambulance was $\leqslant 12$ minutes. When the delay was between eight and 12 minutes only one of the 516 patients survived, with a cerebral performance categories score of III at hospital discharge indicating severe deterioration of cerebral function. Thus, one cannot exclude the possibility that a 12 minute limit is not the true cut off but rather an eight minute limit.

The apparent $J$ shaped curve in fig 1 suggests that survival was higher when the response time was $>20$ minutes than when it was 13-16 minutes. A possible explanation is that some of those survivors with a long response time were in cardiac arrest not at the time of the telephone call for help but rather while the ambulance was on the way to the scene.

In all, 3519 patients fulfilled the criteria (found in a nonshockable rhythm, had a non-witnessed cardiac arrest, had a cardiac arrest at home, and no bystander attempted CPR), accounting for $17 \%$ of all patients with out-of-hospital cardiac arrest in whom CPR was attempted and for whom information on these variables was available.

It may look strange that we found survivors in various subsets when the interval between call for and arrival of the ambulance exceeded 20 minutes. However, one has to keep in mind that survival rate in this subset was always below $1 \%$. These observations suggest that in this subset initiation of CPR by the arriving rescue team may be questioned.

Few previous studies have tried to define subsets of patients in whom initiation of CPR after out-of-hospital cardiac arrest can be regarded as less meaningful. In two previous studies it was found that among patients with nonwitnessed cardiac arrest found in a non-shockable rhythm and older than 80 years, the chance of survival was very low. ${ }^{33} 36$

The vast majority of ambulance organisations participating in this survey had a crew and facilities for treatment with advanced cardiac life support. Thus, among the 479 patients defined as being beyond the potential to survive, $43 \%$ were intubated and 56\% were given adrenaline.

Today, there is no clear evidence that advanced cardiac life support improves survival, ${ }^{37}$ although some indirect findings suggest such a possibility (RA Waalewijn, thesis, 2002:5361).

\section{Implications}

Various ambulance organisations in Sweden have been informed about our results. However, we do not know

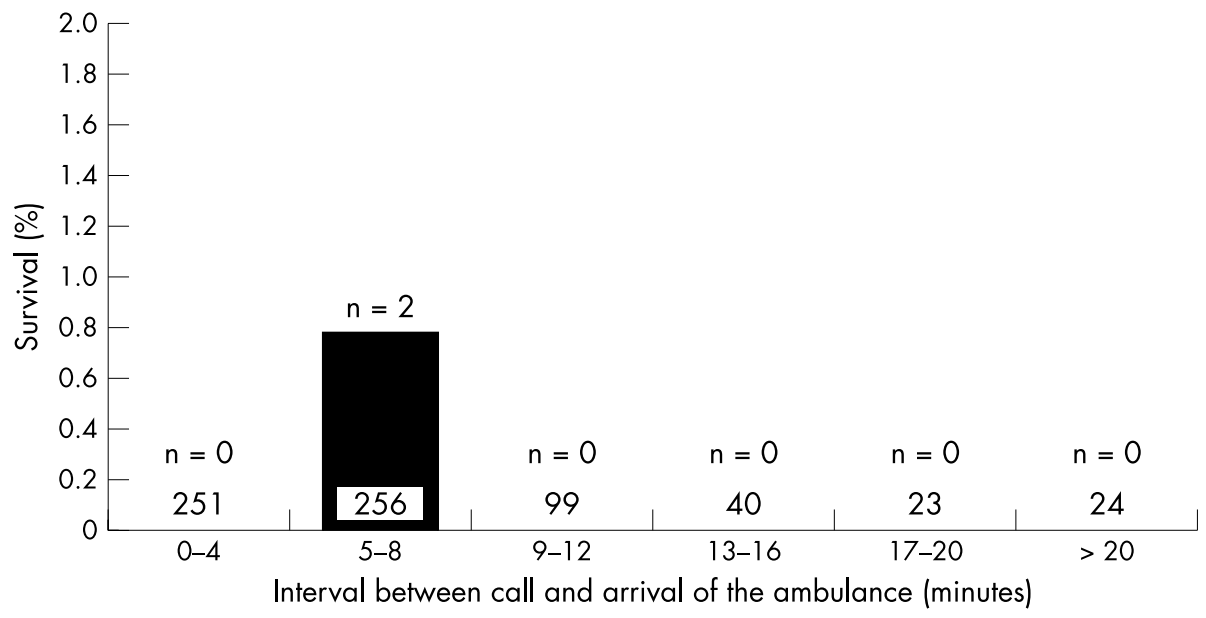

Figure 3 Proportion of patients found in a non-shockable rhythm who did not receive bystander CPR, had a nonwitnessed arrest, had a cardiac arrest at home, and were older than 80 years who survived to one month in relation to interval between call for and arrival of the ambulance. 
whether this has resulted in any change in their routines at present. Our data do not suggest that withholding CPR along these lines will affect a large number of patients.

The psychological impact of "no action" may be considered. It is well known that when a patient dies, the family takes comfort from the feeling that all possible action was taken.

\section{Limitations}

Not all parameters in the decision will be known before resuscitation is attempted, especially for non-witnessed arrest where the nature of the arrest is not immediately clear, while obtaining the first rhythm already initiates the resuscitation.

In 8111 patients $(21 \%)$ the ambulance crew did not initiate CPR and these cases were excluded from analyses for obvious reasons. The reasons for withholding CPR in these cases is not known, although there were clear instructions before the start of the registry when to withhold CPR.

In this survey patients found in asystole were judged to be similar to those found in pulseless electrical activity. However, these two groups have been shown to have a similar prognosis. ${ }^{33} 36$

\section{Conclusion}

Among patients who had an out-of-hospital cardiac arrest who were found in a non-shockable rhythm the following factors were associated with a low chance of survival: no bystander CPR, non-witnessed cardiac arrest, arrest occurring at home, increasing interval between call for and arrival of ambulance, and increasing age. When these factors were considered simultaneously, groups with no survivors were defined. In such groups the ambulance crew may refrain from starting CPR.

\section{ACKNOWLEDGEMENTS}

This study was supported by grants from the Swedish Heart and Lung Foundation.

\section{Authors' affiliations}

J Herlitz, J Engdahl, S Holmberg, Division of Cardiology, Sahlgrenska University Hospital, Göteborg, Sweden

L Svensson, Division of Cardiology, South Hospital, Stockholm, Sweden M Young, Division of Anaesthesiology, Malmö University Hospital, Malmö, Sweden

K-A Ängquist, Surgical Department, Norrland's University Hospital, Umeå, Sweden

\section{REFERENCES}

1 Holmberg M, Holmberg S, Herlitz J, et al. Survival after cardiac arrest outside hospital in Sweden. Resuscitation 1998;36:29-36.

2 Stiell IG, Wells GA, DeMaio VJ, et al. Modifiable factors associated with improved cardiac arrest survival in a multicenter basic life support/ defibrillation system: OPALS study phase I results. Ontario prehospital advanced life support. Ann Emerg Med 1999;33:44-50.

3 Waalewijn RA, de Vos R, Koster RW. Out-of-hospital cardiac arrests in Amsterdam and its surrounding areas: results from the Amsterdam resuscitation study (ARREST) in 'Utstein' style. Resuscitation 1998;38:157-67.

4 Myerburg RJ, Fenster J, Velez M, et al. Impact of community-wide police car deployment of automated external defibrillators on survival from out-ofhospital cardiac arrest. Circulation 2002;106:1058-64.

5 Swor RA, Boji B, Cynar M, et al. Bystander vs EMS first-responder CPR: initial rhythm and outcome in witnessed nonmonitored out-of-hospital cardiac arrest. Acad Emerg Med 1995;2:494-8.

6 Pepe PE. Cardiac arrest presenting with rhythms other than ventricular fibrillation: contribution of resuscitative efforts toward total survivorship. Crit Care Med 1993;21:1813-4.
7 Eisenberg MS, Mengert TJ. Cardiac resuscitation. N Engl J Med 2001;344:1304-13.

8 Holmberg M, Holmberg S, Herlitz J. Incidence, duration and survival of ventricular fibrillation in out-of-hospital cardiac arrest patients in Sweden. Resuscitation 2000;44:7-17.

9 Silfvast T. Initiation of resuscitation in patients with prehospital bradyasystolic cardiac arrest in Helsinki. Resuscitation 1990;19:143-50.

10 Cummins RO, Hazinski MF. Resuscitations from pulseless electrical activity and asystole: how big a piece of the survivors' pie? [editorial]. Ann Emerg Med 1998;32:490-2.

11 Herlitz J, Ekström L, Wennerblom B, et al. Predictors of early and late survival after out of hospital cardiac arrest in which asystole was the first recorded arrhythmia on scene. Resuscitation 1994;28:27-36.

12 Herlitz J, Ekström L, Wennerblom B, et al. Survival among patients with out-ofhospital cardiac arrest found in electromechanical dissociation. Resuscitation 1995;29:96-106.

13 Weston CF, Jones SD, Wilson RJ. Outcome of out-of-hospital cardiorespiratory arrest in south Glamorgan. Resucitation 1997;34:227-33.

14 Herlitz J, Andersson E, Bang A, et al. Experiences from treatment of out-ofhospital cardiac arrest during 17 years in Göteborg. Eur Heart J 2000;21:1251-8

15 Herlitz J, Engdahl J, Svensson L, et al. Decrease in the occurrence of ventricular fibrillation as the initially observed arrhythmia after out-of-hospital cardiac arrest during 11 years in Sweden. Resuscitation 2004:60:283-90.

16 Lombardi G, Gallagher J, Gennis P. Outcome of out-of-hospital cardiac arrest in New York City. The pre-hospital arrest survival evaluation (PHASE) study. JAMA 1994;271:678-83.

17 Good P. Permutation test. A practical guide to resampling methods for testing hypotheses. New York: Springer, 2000:36-7.

18 Smith JP, Bodai BI. Guidelines for discontinuing prehospital CPR in the emergency department: a review. Ann Emerg Med 1985;14:1093-8.

19 Kellermann AL, Staves DR, Hackman BB. In-hospital resuscitation following unsuccessful prehospital advanced cardiac life support: "heroic efforts" or an exercise in futility? Ann Emerg Med 1988;17:589-94.

20 Bonnin MJ, Swor RA. Outcomes in unsuccessful field resuscitation attempts. Ann Emerg Med 1989;18:507-12.

21 Lewis LM, Ruoff B, Rush C, et al. Is emergency department resuscitation of outof-hospital cardiac arrest victims who arrive pulseless worthwhile? Am J Emerg Med 1990;8:118-20.

22 Gray WA, Capone RJ, Most AS. Unsuccessful emergency medical resuscitation: are continued efforts in the emergency department justified? N Engl J Med 1991;325:1393-8.

23 Bonnin MJ, Pepe PE, Kimball RT, et al. Distinct criteria for termination of resuscitation in the out-of-hospital setting. JAMA 1993;270:1457-62.

24 Kellermann AL, Hackman BB, Somes G. Predicting the outcome of unsuccessful prehospital advanced cardiac life support. JAMA 1993;270:1433-6.

25 McIntyre KM. Loosening criteria for withholding prehospital cardiopulmonary resuscitation. Arch Intern Med 1993;153:2189-92.

26 Spaite DW, Hanlon T, Criss EA, et al. Prehospital cardiac arrest: the impact of witnessed collapse and bystander CPR in a metropolitan EMS system with short response times. Ann Emerg Med 1990;19:1264-9.

27 Becker LB, Ostrander MP, Barrett J, et al. Outcome of CPR in a large metropolitan area-where are the survivors? Ann Emerg Med $1991 ; 20: 355-61$

28 Kuisma M, Jaara K. Unwitnessed out-of-hospital cardiac arrest: is resuscitation worthwhile? Ann Emerg Med 1997;30:69-75.

29 Litwin PE, Eisenberg MS, Hallstrom AP, et al. The location of collapse and its effect on survival from cardiac arrest. Ann Emerg Med 1987; 16:787-91.

30 Herlitz J, Eek $M$, Holmberg $M$, et al. Characteristics and outcome among patients having out of hospital cardiac arrest at home compared with elsewhere. Heart 2002;88:579-82.

31 Valenzuela TD, Roe DJ, Cretin S, et al. Estimating effectiveness of cardiac arrest interventions: a logistic survival model. Circulation 1997:96:3308-13.

32 Herlitz J. Survival in patients found to have ventricular fibrillation after cardiac arrest witnessed outside hospital. Eur Heart J 1994;15:1628-33.

33 Engdahl J, Bang A, Lindqvist J, et al. Can we define patients with no and those with some chance of survival when found in asystole out of hospital? Am J Cardiol 2000;86:610-4

$34 \mathrm{Kim}$ C, Becker L, Eisenberg MS. Out-of-hospital cardiac arrest in octogenarians and nonagenarians. Arch Intern Med 2000;160:3439-43.

35 Wuerz RC, Holliman CJ, Meador SA, et al. Effect of age on prehospital cardiac resuscitation outcome. Am J Emerg Med 1995; 13:389-91.

36 Engdahl J, Bång A, Lindqvist J, et al. Factors affecting short- and long-term prognosis among 1069 patients with out-of-hospital cardiac arrest and pulseless electrical activity. Resuscitation 2001;51:17-25.

37 Holmberg M, Holmberg S, Herlitz J. Low chance of survival among patients requiring adrenalin or intubation after out-of-hospital cardiac arrest in Sweden. Resuscitation 2002;54:37-45. 